Doç. Dr. Can DikeR / Bilgi, Duygu ve Arzunun Oluşturduğu Yapay Zekâ'nın Belirsiz

Geleceği: "Artificial Intelligence" (2001) Filmi Örneği

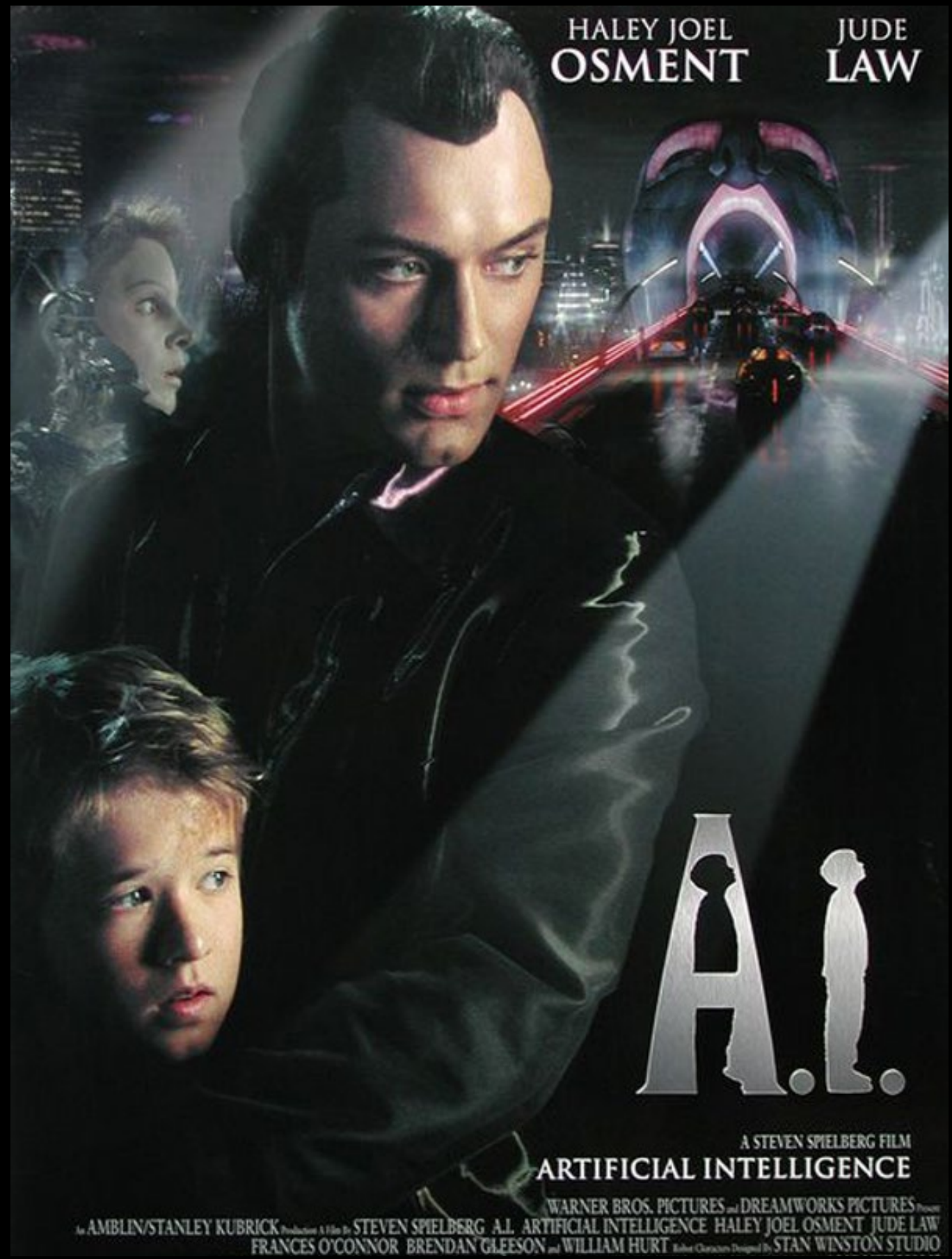




\section{Bilgi, Duygu ve Arzunun Oluşturduğu Yapay Zekâ'nın Belirsiz Geleceği: “Artificial Intelligence" (2001) Filmi Örneği}

\section{Can DiKER*}

Bir süredir edebiyatta ve sinemada insan yapımı bir nesnenin öz bilincine kavuşarak zekâ sahibi olması ve genellikle yaratıcısına karşı çıkması konusu sıkça rastlanan bir tema hâline gelmiştir. 1818'de Mary Shelley'in ünlü Frankenstein romanından 2015'teki Ex Machina filmine kadar yapay zekâ fikrinin ön planda olduğu pek çok yapım bulunmaktadır. Yapay zekâlar kimi zaman da filmlerde yan rollerde görülür. Netflix'in en pahalı yapımları arasında yer alan Altered Carbon (Değiştirilmiş Karbon) dizisinde de otel işleten bir yapay zekânın yan roldeki varlığını görürüz. Benzer şekilde, Christopher Nolan'ın Interstellar filmindeki TARS isimli robot da filmin hikâyesinde kritik roller üstlenir. 1973'te filmi çekilen, 2016'da ise diziye uyarlanan Westworld isimli dizide de yapay zekâya sahip robotların tema parkta bilinç kazanması üzerine gelişen olaylar aktarılmaktadır. Yapay zekâya dair diğer popüler filmler arasında Terminatör, Star Trek, Star Wars, Ben Robot, Blade Runner ve elbette ki Matrix bulunur. Bilinç kazanan robotların insanlığın sonunu getireceğine dair olan inanışın genel olarak filmlerin temasına işlendiği görülür. Eğer insanlığın sonunu getirmiyorlarsa bile, insanların kendilerinden sürekli olarak daha fonksiyonel ve zeki olan bu varlıklara karşı olan tiksinti duygusuna da zaman zaman yer verilmektedir. Yapay Zekâ ile ilgili filmlerin tarihsel konum olarak "Teknolojik Tekillik" (Technological Singularity) denilen, yapay zekânın insan zekâsından daha üstün konuma geçtiği anın ya öncesinde ya da sonrasında bulunduğu görülür. Bu yazıda ise Steven Spielberg'in döneminde çok popüler bir hâle gelen ve yapay zekâların gündelik yaşam pratiğindeki konumunu fütüristtik bir biçimde anlatan Artificial Intelligence (Yapay Zekâ) filmi üzerinden odaklanılıp sinema ve yapay zekâ ilişkisi üzerine değerlendirme yapılacaktır.

Steven Spielberg'in yönetmenliğini yaptı̆̆ 2001 yapımı Artificial Intelligence fil-

* Doç. Dr. Üsküdar Üniversitesi, Iletişim Fakültesi ORCID: 0000-0001-8132-5330 DOI: 10.37679/trta.1002531 
mi, David isimli bir yapay zekâ çocuk robotun hikâyesini anlatmaktadır. Film, gelecekte bir tarihte küresel ısınmanın ardından suların yükselmesi sebebiyle bazı şehirlerin denizler altında kaldığına dair distopik bir anlatıyla başlar. Yapay zekâya sahip robotların, insanların isteklerine ve ihtiyaçlarına yönelik olarak kullanılmaya başlandığını anlatan ilk sahnede, çocuksuz çiftlerin ihtiyaçlarını karşılamak üzere bir robot prototipine "duygu" eklemesi yapılacağı ve bu robotun bir çocuk imitasyonunu gerçekleştireceği anlatılır. Diğer robotlardan farklı olarak sadece bilişsel kapasitesi ile değil, sonsuz duygusal kapasitesi ile de ön plana çıkacak olan çocuk robotların da arz edileceğinden bahsedilir. İlk prototipin denemesini gerçekleştirmek için gerçek oğulları komada olan Monica ve Henry çifti seçilir. David isimli çocuk robot, Monica tarafindan aktifleştirildikten sonra ona sonsuz bir sevgi duymaya başlar. Yapay zekânın, bilişsel ve duygusal fonksiyonları birlikte çalışırken, David'in "annesine" sorduğu ilk sorulardan birisi ömrünün ne kadar uzun olacağıdır. Ölüm bilincine sahip bir yapay zekânın sevdiği kişinin ölümünden korkması, filmin son kısmı için olacakların habercisidir. Monica, David’e arkadaşlık etmesi adına oğlunun eski bir oyuncağı olan Teddy isimli robotu verir.

Swinton ailesi için her şey yolunda giderken bir gün oğulları Martin'in komadan çıkması ve eve geri gelmesiyle işler değişir. Martin, bir gün annesinden Pinokyo masalını kendilerine okumasını ister. Ahşap bir kuklanın gerçek bir çocuğa dönüşmesi hikâyesine müthiş bir ilgi duyan David, mucizeyi gerçekleştiren Mavi Peri'yi hafizasına kaydeder. Bu esnada Martin, David'e giderek rekabet kavramını öğretecek şekilde davranışlar sergiler ve onun kendisiyle rekabete girmesini sağlayıp başının derde girmesine yol açar. Martin'in manipülasyonları ve sataşmaları David üzerinde sonuç verir. David'i yemek yemeye zorlayarak arızalanmasına sebep olur ve kıskançlık hissiyatının tetiklenmesini sağlar. Bir gün, Martin, David'e annesi Monica'yı eğer seviyorsa onun saç telinden kendisine getirmesi gerektiğini söyleyerek babası ve annesi gözünde bu eylemin bir öldürme teşebbüsü olarak ve David'in "hatalı ürün'” olarak düşünülmesine yol açacak olaylar silsilesini başlatmış olur. Kesilen saçı ise o anda Teddy alıp saklar. Hâlbuki David'in tek istediği şey, programlandığı üzere Monica'nın sevgisine sahip olmaktır. Bir gün havuz başında verilen bir partide Martin'in arkadaşlarından birisi David'e zarar vermeye çalışınca David'in Martin'i güvenlik protokolü esnasında az kalsın boğuyor olması, kendisine tanınan son hak olur. Monica, ertesi gün David'i yok etmeleri üzere Cybertronics firmasına geri götürmek için yola çıkar. Varmak üzereyken Monica, David'in yok olmasına razı olamaz ve ormanlık bir alanda kendisini bırakır. David, Monica'dan ayrılmak istemez ve annesinin sevgisine layık olmak için çok daha iyisini yapacağını tıpkı gerçek bir çocuk gibi yalvararak ve ağlayarak söylese de 
Monica ağlayarak kendisini Teddy ile birlikte ormanda terk eder. Filmde bu noktaya kadar Monica'yı rahatsız eden unsurun, David'in robot olduğunu bilinmesine rağmen önceden tanımlı birtakım ağlama, çığlık atma, üzülme gibi eylemleri birebir taklit edebilme yeteneğidir. David'in taklitleri elbette ki bir simülasyondur ve bir insan duygusuyla doğrudan bağlantılı değildir. Monica'nın David’i bırakabilmesindeki en büyük etken de budur: İnsan (ya da gerçek) olmamak.

Hikâye, buradan itibaren ikinci bir yapay zekâ robotu anlatmaya başlar. Jigololuk yapan Joe isimli robot, bir anda kendisini bir cinayet komplosunun içinde bulur. Müşterilerinden birisini ölü olarak bulan Joe, kadının eşinin cinayeti üzerine yıkmak istediğini fark eder ve olay yerinden kaçmaya başlar. Bu esnada David, Pinokyo hikâyesinden ilham alarak eğer gerçek bir çocuk olursa rasyonel bir bağlamda annesinin de kendisini seveceği çıkarımını yapar. Bunu gerçekleştirmek üzere, hikâyede bahsi geçen Mavi Peri'yi aramaya karar verir. Ormanda ilerlerken aralarında Joe'nun da olduğu bir grup kaçak, gözden çıkarılmış ve parçaları eksik robot grubuyla karşılaşır. Cybertronics çöpleri arasından kendilerine uygun el, kol protezleri gibi çeşitli parçaları arayan robotların çöplükteki arayışı, Lord Johnson-Johnson öncülügündeki robot karşıt bir avcı grubu tarafindan kesilir. Robotları yakalayan avcı grup, "Et Fuarı” adını verdikleri mekâna robotları götürerek onları orada seyircilerin önünde parçalamak için sıraya yerleştirir. Lord Johnson-Johnson, çocuk robotu seyircilere göstererek robot firmalarının etik dışı eylemlerine dikkat çekmeye çalışsa da üzerine birkaç damla asit dökülen David'in gerçek bir çocuk gibi ağlaması seyirciyi beklenmedik bir biçimde harekete geçirir ve robot avcısı ekibe saldırmalarına neden olur. Ortamdan birlikte kaçan iki yapay zekâ Joe ve David, birlikte Kırmızı şehre doğru yol alırlar. Joe, kırmızı şehirdeki Dr. Know’un Mavi Peri'yi nerede bulabileceğini David'e söyler ve birlikte bir dijital ansiklopedi görev olan Dr. Know’a Mavi Peri'yi sorarlar. Dr. Know, "dünyanın sonunda aslanların ağladığı yerde" Mavi Peri'yi bulabileceklerini söylediğinde, aslında sular altında kalmış New York şehrine, 'Manhattan'a gitmeleri gerektiğini öğrenmiş olurlar. Joe'yu almaya gelen bir polis helikopterini çalarak New York’a birlikte uçarlar. Filmin ikinci bölümünde de görüleceği üzere, taklit yeteneği mükemmel olmasına rağmen gerçek olmadığı için terkedilen David'in gerçek olma arayışının tecrübe üzerine şekillendiği görülür. Yakalandıktan sonra yok olma tehlikesiyle karşı karşıya kalan David, o güne kadar öğrendiklerini doğaçlama yeteneğiyle sunma şansı yakalar ve izleyici kitlesinin kendisini "gerçek" sanmasına yol açarak kaçması için firsat yaratmış olur. Bu bağlamda Spielberg, filmin ilk iki bölümünde bir zekânın gerçek ya da gerçek dışı olup olmamasını aslında yaşam tecrübesine bağlamaktadır. Teorinin değil, uygulamanın önemi aslında gerçekliğin yakalanmasında kilit roldedir. 
David ve Joe, burada Cybertronics firmasının New York'taki binasına girerler. David, burada Profesör Hobby ile karşılaşır ve Mavi Peri hikâyesinin bir mit olduğunu, Dr. Know'un ise kaçak konumda olan David'i kendisine getirmek için kullandığını öğrenir. David, mekanik atölyede kendisinin onlarca farklı klonunu gördüğünde şaşırır. Kutulanmış bir şekilde erkek çocuklar David, kız çocuklar Darlene isminde yeni sahiplerine gönderilmeyi beklemektedir. Hiçbir zaman gerçek bir insan olamayacağını düşünen David, kendini oldukça kötü hissederek gökdelenin tepesinden kendisini suya bırakır. Dibe doğru giderken aşağıda bir lunaparkı gören David'i Joe’nun kullandığı helikopter kurtarır. David, lunaparkta Mavi Peri'nin olduğunu söyleyerek oraya gitmeleri gerektiğini belirtir. Helikopter, bir denizaltına dönüşürken Joe o esnada cinayetten polisler tarafindan yakalanır ancak David ve Teddy, denizaltını aşağıdaki lunaparka gitmek için kullanarak olay yerinden uzaklaşırlar. Sular altındaki lunaparkta Pinokyo temalı parkta porselenden yapılmış bir Mavi Peri heykelini bulan David ve Teddy, denizaltının üzerine dev bir dönme dolabın düşmesiyle sualtında mahsur kalırlar. David, porselenden heykele kendisini gerçek bir çocuğa dönüştürmesi için sürekli yalvarmaya başlar ve bu şekilde uzun bir süre boyunca David, Mavi Peri'den dileğini gerçekleştirmesini bekler. Filmin bu noktası ise tüm çözüm yolları tükenen bir yapay zekânın sonsuz bir döngüye girmesini gösterir. Gerçeklikten uzak bu nokta ise, filmin geri kalanıyla birleştiğinde insanlık tarihi için önemli sonuçlara yol açacaktır.

Filmin hikâyesi, iki bin yıl sonrasına doğru büyük bir sıçrama gerçekleştirir. Dünya buzul çağına girmiş ve insanlığın nesli tamamen yok olmuştur. Uzaylı varlıklar, dünyaya gelerek insanlıktan kalan kültürel mirasları toplamaya çalışmaktadır. Uzaylıların bu esnada donmuş bir biçimde denizaltında mahsur kalan David ve Teddy'i buldukları görülür. Yapay zekâ robota özel ilgi gösteren uzaylı varlıklar, onların çözünmesini sağlayarak tekrardan aktifleşmelerini sağlarlar. David, bunca zaman geçmiş olsa da hâlen annesinin sevgisini aramaktadır. Binlerce yıl sonra Mavi Peri heykeline dokunma şansı yakalayan David, heykele dokunduğu anda heykelin parçalanmasına sebep olur. Yaşadığı hayal kırıklığı, kısa süreli kalır. UzayIılar, sahip oldukları bir teknolojiyle insanları diriltmenin bir yolunu bulmuşlardır. Ancak diriltme işleminin bir koşulu, bir de beklenmedik sonucu vardır. Koşul olarak diriltilecek kişinin DNA'sını içeren bir madde gereklidir. Dirilmenin sonucu olarak ise kişi dirilse bile, evrenin çalışma şeklinden dolayı kişi yalnızca sadece bir günlüğüne hayata geri dönmekte, sonrasında ise tamamen yok olmaktadır. Teddy, çok uzun zaman önce sakladığı Monica'nın saç telini David’e verir. David, annesinin tamamen yok olacağı bilgisine rağmen yine de onun diriltilmesini ister. Yeniden canlanan Monica, David'i hatırlar, onu sevdiğini söyler ve üçü birlikte 
güzel bir gün geçirirler. Gün biterken, Monica sonsuz uykusuna doğru yavaşça kendisini kaptrırken David de sevilmenin verdiği bilinçle o da Monica ile birlikte huzurlu bir şekilde sonsuz bir uykuya doğru dalarken film sonlanır.

Steven Spielberg'in Yapay Zekâ filmi, bize orta vadeli geleceğimize dair belirgin bir öngörü sunar. İnsanlığın kontrolsüz gelişimi ve çoğalması sayesinde dünyanın bir iklim krizine sürüklenmiş olmasıyla birlikte, gelişen teknolojiler insanlığın keskin uçlardaki duygularına hizmet etmek amacıyla kullanılmaktadır. Yapay zekâ robotların insan ihtiyaçlarına hizmet etmesinin normal olduğu bir dönemde, filmin ilgi çekici yanının yapay zekâların duyguları hissetmesi olduğu görülür. Bir yapay zekâ için duygunun anlamı bir insan ile aynı mı olmaktadır? Bu sorunun yanıtını aslında Matrix'in 3. filminde bir yapay zekâ Neo'ya vermektedir: “Sevgi bir insan duygusu değil, bir kelimedir. Önemli olan şey ise o kelimenin vurguladığı bağdır. Âşık olduğun kişiyle bağı tutmak için nelerini vermezsin?" Bu perspektiften ele alındığında, özü gereği yapısalcı bir yaklaşımla dünyayı anlamlandıran yapay zekânın sevgi denen koşulsuz ilişkiyi hâlen belirli sınırlamalar çerçevesinde ele aldığı söylenebilir. Sevginin sınırsız ve koşulsuz bir eylem olarak yapay zekâya tanıtılması, yapay zekânın sahip olduğu bilişsel kapasiteyi doğaçlama yapmak üzere kullanmasına neden olur. Doğaçlama yeteneği, bir filmin anlatısındaki dramatik çatının kurulması için oldukça elverişli bir davranış biçimi hâline gelir. Kendi davranış kalıpları dışında davranmaya itilen robotun beklenmedik olaylara sebebiyet vermesi, "duygu" denen insan dürtüsünün (ya da mekanik bağlamda "anlamı tanımlı" kelimenin) bir sonucudur. Çeşitli film ve dizilerde bu tema görülür: Westworld'de de robotların kendilerine kötü davranıldığını fark etmelerinin ardından isyan ederek kendi kontrollerini ellerine almaları ya da Terminatör filminde Skynet'in insanlığın sonunu getirmesi, benzer şekilde Matrix'te insanlık ile yapay zekâ robotların savaşının dünyanın sonunu getirmiş olması gibi hikâyeler birbiriyle benzerlik taşırlar ve ortak bir yapay zekâ korkusuna da işaret ederler. İnsanlık, kendisinden her an daha zeki, daha enerjik bir zekâ formunu geliştirmiş olsa da yapay zekâların duygusuz yanıtlarının ardındaki tekinsizlik duygusu hemen hemen her filmde ilk zamanlardan itibaren hissedilir. Bir diğer popüler film olan Ex Machina'da olduğu üzere âşık olma simülasyonu bile yapan bir yapay zekânın kendi özgürlüğü için insanları kullanması, yapay zekâların ahlak problemini izleyiciler önüne sermektedir. Robotlar, talepleri ne olursa olsun tamamen insanlığa hizmet mi etmelidirler yoksa Asimov'un robot yasalarından üçüncüsüne ters olacak bir biçimde, kendi iradeleri de bir yaşam formu olarak sayılıp kendilerine özgü bir "meşru müdafaa" mı gerçekleştirmelidirler?

Spielberg'in Yapay Zekâ filmi, robot ahlakı ve insanların robotlara karşı olan huzursuz yaklaşımı konusunda derinlemesine bir anlat gerçekleştirmez. Hikâye, daha 
çok bir robotun "önceden tanımlanan" sevgi kavramına yönelik olan doğaçlama yaklaşımı üzerinde bir anlat gerçekleştirir. Annesi olarak tanımladığı Monica için sonsuz sevgi duyduğu gösterilen David'in, sevginin karşılığını alabilmek adına aldığı riskler film boyunca anlatılır. Filmde, diğer yapay zekâya sahip robotların da orijinal olarak neye programlandılarsa onu elde etmeye yönelik amaçlarına ulaşmak için hayatın çok bilinmeyen denklemli yapısında doğaçlama yapıp tecrübe kazanmaları gösterilir. Bu bağlamda izleyiciler kaçınılmaz olan empatiyi yapay zekâ robotlarla da rahatlıkla kurmaya başlarlar: Yapay zekâlar da tıpkı insanlar gibi içinde bir anda belirdikleri dünyayı tanımak, ona adapte olmak ve kendi varoluşlarını korumaları gerekmektedir. Bir anlamda pek çok filmde bir alt felsefe olarak yapay zekâ robotların varoluşçuluk felsefesini benimsedikleri söylenebilir. Böylece izleyicilerin önünde yapay zekâlardan nerelerde farklılaştkkları ve yapay zekâlarla nerelerde benzeştiklerine dair geniş bir seçki yaratılmış olunur. Yapay zekânın alametifarikasının öz bilince sahip olmak olduğunu düşündüğümüzde, aslında ontolojik bağlamda insan ile robotların arasında çok fark olmadığına dair yüzeysel bir çıkarsama yapılabilmektedir. Yapay zekâlar insanlara göre sürekli olarak daha akılcı davranırken ve mevcut durumlara olan adaptasyonu çok daha hızlı gerçekleştirebilirken insanlar daha kurnaz, sinsi ve kötücül olarak film anlatılarında yer alabilmektedir. Bu bağlamda, insan davranışının kökenini sorguladığımızda, Nietzsche'nin de iyinin ve kötünün ötesinde olduğunu vurguladığı üzere insanın mutlak güç istencinin olduğu görülmektedir. Güç istenci, insanın arzularını ve tutkularını yönlendirir, bireylere iktidar alanı sağlar ve efendi ahlakı veya köle ahlakı gibi felsefede derinlemesine tartışılan ahlak biçimlerinin ortaya çıkışına neden olur. Hatta Fransız filozof Deleuze, insanları birer arzu makinesi olarak tanımlarken makinelerde insanlardaki gibi bir güç istenci olmaması dikkat çekicidir. Yapay zekânın güç istencine sahip olmasına dair en belirgin örnek olarak Matrix filmindeki “Mimar'”olarak bilinen yapay zekânın bir tanrı kompleksine sahip olduğu anlaşılsa da Kâhin karakterinin, Mimar'ın güç arzusunu kaotik bir biçimde yıkmaya çalışıp denklemi eşitlemeyi görev edindiği görülür. Dolayısıyla, yapay zekâ filmlerinin anlatısında temel olarak iki farklı tip vurgu yapılır: Birincisi; insanın yaratıcı olarak konumlandığı, yapay zekânın da ona mahkûm olduğu bir anlat, ikincisi ise yapay zekânın insandan daha üst bir konuma geçmesi ve onun yaratıcı hâline gelmesini aktaran bir diğer anlat. Spielberg'in Artificial Intelligence filmi ilk tür filmlerdendir, Ex Machina ve Matrix gibi filmler ise ikinci türe aittir. Özellikle Matrix filminde vurgulandığı gibi, insanlar ile yapay zekâ robotlar arasında çıkacak bir savaşın ardından insanların makinelerin esiri olduğu ve bir simülasyon içinde hayal görmeleri sağlanarak tarlalarda enerjilerinin pil amaçlı olarak kullanıldığına yönelik anlat, insanlık için en kötü senaryoya sahiptir diyebiliriz. 
Dolayısıyla, Asimov'un yakın bir gelecekte robotların organikleşeceği, insanların da robotlaşacağı ve bu yakınsamanın sonuçlarının sorgulanması gerektiğine dair öngörüsü, teknolojinin de gelişim hızı hesaba katıldığında 21. yüzyılın sonlarına doğru önemli bir konu olarak gün geçtikçe artan bir biçimde tartışılacaktır. Teknolojik Tekillik anının aşılmasının ardından Stephen Hawking veya Elon Musk gibi önemli figürlerin kötü bir senaryoda insan ırkının sonunun gelebileceğini belirttikleri görülür. Başka teorisyenler, Teknolojik Tekillik anını insanlığın evriminin bir sonraki basamağı olarak görerek biyo-insanın ortaya çıkışından bahsederler. Moleküler nanoteknoloji sayesinde süper-zekâ hâline gelen ve yarısı makineleşmiş insanlığın artık yeni bir ırk olarak, Nietzsche'nin bir anlamda süper insanına dönüşmesi de söz konusudur. Dolayısıyla en iyi senaryoda insanlar makineleşerek evrimsel olarak çok hızlı bir biçimde ilerleyecek ya da en kötü senaryoda makineler, birtakım hesaplamaların ardından insanlığa savaş açmaya karar vererek insanlık ırkını köleleştirecek ya da yok edecektir. Her iki anlamda da, şu anki insanlık fikrinin zedeleneceği söylenebilir. Filmlerde de yapay zekâlara dair emirlere saygılı ancak tekinsiz anlatıların kendi içinde giderek artacağı ve hatta güç istencine sahip robotların nasıl bilişsel ve duygusal olarak böyle bir düşünüş biçimine sahip oldukları üzerine çeşitli anlatılar görülebilecektir. Bu bağlamda Spielberg'in Aritifical Intelligence filmi, uzun bir zaman akışına sahip olarak yapay zekâ robotların insanlık için ileri gelecekteki önemine de değinmiş ve önceden tanımlanmış amaca yönelik olarak robotların nasıl bilişsel kapasitelerini bu arzuya yönelik olarak kullandıklarını da oldukça başarılı bir şekilde göstermiştir. Önemli bir kilometre taşı olarak değerlendirebileceğimiz Artifical Intelligence filmi, şüphesiz ki yapay zekâ üzerine hâlen günümüzde konuşulan ve sonraki filmlere de ilham kaynağı olabilecek bir öngörüye sahiptir. Günümüzden itibaren hem yapay zekâ alanındaki hem de sinema teknolojisindeki gelişmeler dâhilinde anlatıları zenginleşecek olan gelecekteki yapay zekâ filmlerinde de Spielberg'in çizdiği yapay zekâ profilinin mirasından çeşitli izlekler görmek şaşırtıcı olmayacaktır. 